\title{
Research priorities in rehabilitation medicine
}

\author{
Walter R. Frontera \\ School of Medicine, University of Puerto Rico, San Juan, Puerto Rico
}

The importance of scientific research in the field of rehabilitation medicine (RM), and in rehabilitation in general, is a matter of great interest. Significant attention has been given to this subject in recent international meetings. Thus, it is timely to consider the reasons to foster research activity and to develop a stronger scientific base for the practice of RM. Many professional disciplines are an integral part of the practice of rehabilitation. Although my editorial comments may relate more to the medical aspects of our practice, they should be considered in the context of a multidisciplinary and interdisciplinary activities (Bakheit, 2009).

According to Nobel laureate Medawar (1979), scientific research is an exploratory activity of which the purpose is to come to a better understanding of the natural world. The outcome of research is knowledge hard won, in which we have much more confidence than we have in opinion, hearsay, and belief. Research is essential for the development of any profession because a profession is a calling requiring specialized knowledge and long and intensive instruction in skills and methods as well as in the scientific, historical, or scholarly principles underlying such skills and methods (Webster's, 1986). Those who practice RM must have confidence in our understanding of fundamental concepts, such as function, that define what we do. Research stands for the way and means to achieve that confidence.

The survival of the field of RM and the relevance of its contribution to society depends, to a significant degree, on the performance of research and the translation of research findings into practices that become standards of clinical services in healthcare systems. At least two important priorities must be considered by all interested in the future of the field: building research capacity and defining a research agenda. Building research capacity depends on several factors, such as (i) the recruitment and retention of junior and senior talented investigators to the field including training programs for interested students; (ii) the development of a research infrastructure (space, equipment, etc.) together with an institutional culture that values scientific inquiry; (in) the provision of adequate funding to support the effort; and (iv) the establishment of research collaborations and partnerships with colleagues in other scientific fields and with the community (Frontera et al., 2005). Institutions and individuals interested in RM must make a commitment to support and actively participate in all these efforts.

The scientific agenda must be defined based on the knowledge gaps in rehabilitation and the needs of our patients. Basic science research in rehabilitation must be supported while integrating approaches that are common to other health professions and medical specialties. Clinical and translational research must occupy a special place in the research agenda. In other words, we need to make sure that our research is designed to translate basic science findings into clinical knowledge useful and applicable in health delivery systems for the benefit of people with disabilities. Some areas of research compatible with this model include the 
following: genetic determinants of rehabilitation interventions, neuroregeneration, tissue engineering, nanotechnology, outcomes research, and the development of methods to measure functional capacity. Clearly, this is not an exhaustive list and many other important and related topics can be added, such as the aging population. The field of RM should take advantage of the dramatic increase in general scientific knowledge, advances in research methodology, and technological innovations to enhance rehabilitative efforts and the quality of life of all in need.

It is clear that the field of rehabilitation research in general and RM in particular have made significant progress in the last decade. Nevertheless, it is imperative that we do more. Our contribution to a better future society without barriers depends on it.

\section{References}

Bakheit AM. Creating the optimal conditions for rehabilitation research. Int J Rehabil Res 2009;32:185188. [PubMed: 19685576]

Frontera WR, Fuhrer MJ, Jette AM, Chan L, Cooper RA, Duncan PW, et al. Rehabilitation medicine summit: building research capacity (executive summary). Am J Phys Med Rehabil 2005;84:913-917. [PubMed: 16327406]

Medawar, PB. Advice to a Young Scientist. New York: Harper Colophon Books; 1979.

Webster's Third New International Dictionary of the English Language. Chicago: Encyclopedia Britannica; 1986. 